\title{
Effect of trolox and quercetin on sulfur mustard-induced cytotoxicity in human peripheral blood lymphocytes
}

\author{
R. Bhattacharya, R. K. Tulsawani, R. Vijayaraghavan
}

Division of Pharmacology and Toxicology, Defence Research and Development Establishment, Jhansi Road, Gwalior-474002, Madhya Pradesh, India.

Received: 23.7.2005

Revised: 30.9.2005

Accepted: 16.12.2005

Correspondence to: R. Bhattacharya E-mail: rbhattacharya41@rediffmail.com

\begin{abstract}
Objective: To evaluate the protective activity of antioxidants, viz. trolox and quercetin, against sulfur mustard (SM)-induced cytotoxicity.

Materials and Methods: Cytotoxicity of various concentrations (20-640 $\mu \mathrm{M})$ of SM, in the presence or absence of $10 \mu \mathrm{M}$ trolox or quercetin $(-0.5,0$, or $+0.5 \mathrm{~h})$ was determined in human peripheral blood lymphocytes after 6-h exposure. Cell viability was measured by Trypan blue dye exclusion (TBDE). Further, a cytotoxic concentration of SM (80 $\mu M)$ was challenged by the two antidotes $(-0.5 \mathrm{~h})$ and cell viability was measured by TBDE and leakage of intracellular lactate dehydrogenase (LDH). Mitochondrial integrity and peroxide levels were measured by 3-4,5-dimethyl thiazol-Z-yl)-2,5-diphenyltetrazolium bromide and 2',7'dichlorofluoroscin diacetate assay, respectively. Morphological changes of cells exposed to $320 \mu \mathrm{M}$ SM (with or without antidotes) were also visualized under light microscope.

Results: On the basis of TBDE, SM caused cell death of approximately $50 \%$ at $80 \mu \mathrm{M}$ and $100 \%$ at $640 \mu \mathrm{M}$, respectively. Pretreatment of trolox conferred significant protection compared with quercetin. Also, pretreatment of trolox significantly reduced cell death and LDH leakage caused by $80 \mu \mathrm{M}$ SM but did not prevent the loss of mitochondrial integrity. Trolox significantly reduced the levels of peroxides generated by SM. The better protection offered by trolox was evidenced in cell morphology studies too.

Conclusion: Pretreatment $(-0.5 \mathrm{~h})$ of trolox afforded significant protection against SM-induced cytotoxicity in human lymphocytes. The protection was related to the antioxidant property of trolox, a water soluble analog of $\alpha$-tocopherol.
\end{abstract}

KEY WORDS: Alkylating agent, antioxidant, cytotprotective, WBC

\section{Introduction}

Although India is a signatory to the Chemical Weapons Convention, threat from unscrupulous use of sulfur mustard (SM; bis [2-chloroethyl] sulfide), a potential chemical warfare agent still persists. ${ }^{[1,,[2]} \mathrm{SM}$ is a highly reactive bifunctional alkylating agent that causes blisters and several other injuries on exposure. ${ }^{[3]-[5]} \mathrm{SM}$ forms sulfonium ion in the body and alkylates DNA, leading to strand breaks and cell death. ${ }^{[3],[5]}$ Owing to the high electrophilic property of the sulfonium ion, SM binds to several cell components and causes various toxic

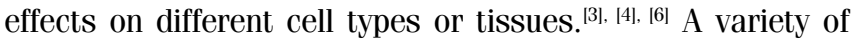
substances such as free radical scavengers, inhibitors of cell death, promoters of cell survival, radioprotectors, and numerous other pharmacological agents of diverse action have been shown to attenuate SM toxicity in vivo and in vitro. ${ }^{[7]-[12]}$ Protective effects of various antioxidants, viz. vitamin E, glutathione, and thiol reagents such as dithiothreitol and $\mathrm{N}$-acetylcysteine (NAC) have also been reported against toxicity of SM or its analogs. ${ }^{[13],[14]}$ However, none of the agents have been approved for human use so far.

The best protection against SM poisoning is avoidance of contact and in the event of contact, rapid decontamination or detoxification of the contaminated area should be done. Only a few chemical decontaminants for human use have shown very good efficacy. ${ }^{[15],[16]}$ The possible strategies to counter SM poisoning include (i) prevention of SM-induced alkylation of macromolecules, (ii) reversal of alkylation, and (iii) prevention or reversal of cascade of biochemical events following alkylation. Clinical manifestation of SM exposure is delayed and often has an extended latent phase of injury. ${ }^{[6]}$ In view of this, many researchers have proposed prophylaxis as a more pragmatic approach for SM poisoning, ${ }^{[7], ~[10], ~[12], ~[14] ~}$ more so because of the risks involved in the destruction of SM or during inspection by the Organization for Prohibition of Chemical Weapons. In the present study, the effect of trolox (a water-soluble analog of $\alpha$-tocopherol; vitamin E) and 
quercetin (a polyphenolic natural bioflavonoid) was evaluated against SM-induced cytotoxicity in human peripheral blood lymphocytes (PBL). Protective efficacy of trolox and quercetin was studied by pretreatment $(-0.5 \mathrm{~h})$, simultaneous treatment $(0 \mathrm{~h})$, or post-treatment $(+0.5 \mathrm{~h})$ to SM exposure.

\section{Materials and Methods}

\section{Chemicals}

Trolox (6-hydroxy-2,5,7,8-tetramethylchroman 2carboxylic acid), quercetin dihydrate (3-3',4',5,7pentahydroxy flavone), MTT (3-4,5-dimethyl thiazol-Z-yl)2,5-diphenyltetrazolium bromide), HEPES (histopaque1077), fetal bovine serum (FBS), phosphate buffered saline (PBS), and Trypan blue were purchased from Sigma-Aldrich (St. Louis, MO, USA). DCFH-DA (2',7'-dichlorofluoroscin diacetate) was from Molecular Probes, USA. Hank's balanced salt solution (HBSS), penicillin, and streptomycin were from Hi Media India Ltd., Mumbai, and other chemicals of highest purity were from BDH or Qualigen India Ltd., Mumbai. Lactate dehydrogenase (LDH) diagnostic kit was purchased from Merck India Ltd., Mumbai. SM was synthesized in the Synthetic Chemistry Division of Defence Research and Development Establishment (DRDE), Gwalior, and was found to be $>99 \%$ pure by gas-chromatography analysis.

\section{Lymphocyte preparation}

Human PBLs were isolated from fresh heparinized venous blood obtained from normal volunteers. ${ }^{[17]}$ Blood was diluted with equal volume of HBSS (pH 7.4) plus 15 mM HEPES. The sample was then layered on HEPES and centrifuged at $400 \mathrm{~g}$ for $30 \mathrm{~min}$ at $18^{\circ} \mathrm{C}$. Lymphocytes were removed from the aqueous Ficoll interface and washed three times with HBSS. Viability of the cells was found to be more than $95 \%$, as determined by Trypan blue dye exclusion (TBDE). ${ }^{[18]}$ Cells were washed in HBSS and treated with equal volumes of TB $(6.2 \mathrm{mM})$ and $\mathrm{NaCl}(0.8 \mathrm{M})$ and gently mixed. After $2 \mathrm{~min}$, cells were counted under inverted microscope (Olympus, Japan) using hemocytometer. The percentage of cells excluding dye was calculated immediately after washing. The cell suspension was diluted to a final density of 1 X $10^{6}$ cells $/ \mathrm{ml}$ of HBSS, containing $15 \mathrm{mM}$ HEPES, 5\% FBS, penicillin (100 U/ml), and streptomycin $(100 \mu \mathrm{g} / \mathrm{ml})$. Aseptic techniques were used throughout the preparation of the lymphocytes. Cells were incubated ( $2 \mathrm{ml} /$ well) in 24 well plates (Nunc, Denmark) maintained at $37^{\circ} \mathrm{C}$ in humidified atmosphere rich in $5 \% \mathrm{CO}_{2}$ $+95 \%$ air.

\section{Treatments}

Preparation of the solutions and concentrations of SM or the antidotes were based on our previous studies. ${ }^{[12], ~[19]}$ Cytotoxicity of various concentrations (20-640 mM) of SM, in the presence or absence of $10 \mathrm{mM}$ trolox or quercetin $(-0.5,0$, or $+0.5 \mathrm{~h})$, was determined in the cells after 6 -h exposure. The control cells and SM-treated cells received equal amounts of PBS at the time points corresponding to the antidote treatments. The cell viability was measured by TBDE. In a separate experiment, a cytotoxic concentration of SM $(80 \mathrm{mM})$ was challenged with pretreatment $(-0.5 \mathrm{~h})$ of 10 $\mathrm{mM}$ trolox or quercetin alone and the cell viability was measured after $6 \mathrm{~h}$ by TBDE and leakage of $\mathrm{LDH}$. At this point of time, mitochondrial integrity and peroxide levels were also measured by MTT and DCFH-DA assay, respectively.

Leakage of $\mathrm{LDH}$

After termination of the experiment, intracellular and extracellular (medium) LDH was estimated by commercial diagnostic kit at a wavelength of $340 \mathrm{~nm}$ using a plate reader (Tecan SPECTRAFluor Plus, Austria). Leakage of LDH was expressed as percentage of the total. ${ }^{[20]}$

MTT assay

Mitochondrial integrity of the cells was measured by reduction of mitochondrial enzyme succinate dehydrogenase by MTT. The MTT reduction was carried out by the method of Mosman. ${ }^{[21]}$ Briefly, MTT was dissolved in culture medium at a concentration of $0.5 \mathrm{mg} / \mathrm{ml}$ and filtered to remove the small amount of insoluble residue. MTT-containing medium was added to each well in a volume of $0.5 \mathrm{ml}$ and incubated for 3 $\mathrm{h}$. Thereafter, the supernatant was removed and $1.25 \mathrm{ml}$ of a solution of $0.4 \mathrm{~N} \mathrm{HCl-isopropanol}(1: 24 \mathrm{v} / \mathrm{v})$ was added to extract and solubilize the formazan. After $0.5 \mathrm{~h}$ at room temperature, the absorbance of the formazan was read at a wavelength of $570 \mathrm{~nm}$ and expressed as $\left({ }_{\Delta} \mathrm{OD}^{570}\right)$.

Measurement of peroxides

The assay is based on the principle that DCFH-DA, a nonpolar and nonfluorescent compound, can diffuse through the cell membrane and deacetylated by cytosolic esterases to yield polar, nonfluorescent DCFH (2', 7'-dichlorofluoroscin). DCFH is trapped within the cytoplasm, where it reacts with peroxides to form DCF (2', 7'-dichlorofluorescein), which can be measured by fluorometer at excitation and emission wavelengths of 500 and $520 \mathrm{~nm}$, respectively. ${ }^{\text {[2] }}$ Cells were centrifuged at $50 \mathrm{~g}$ for $1 \mathrm{~min}$, resuspended in HBSS containing 1.6 $\mu \mathrm{M}$ DCFH-DA, and incubated at $37^{\circ} \mathrm{C}$ for $2 \mathrm{~min}$. At the end of the incubation, the fluorescence intensity was measured and results expressed as percent control.

Photomicrography

In a separate experiment, cells were exposed to $320 \mathrm{mM}$ $\mathrm{SM}$ for $6 \mathrm{~h}$, in the presence or absence of $10 \mathrm{mM}$ trolox or quercetin $(-0.5 \mathrm{~h})$. Cells were stained with Papanicolaou solution $3 \mathrm{~b}$ and observed under light microscope for morphological changes.

Statistical analysis

The results are expressed as mean \pm SEM $(n=4)$. The data were analyzed by one-way ANOVA followed by StudentNewman-Keuls test for comparison. Statistical significance was considered at $\mathrm{P}<0.05$.

\section{Results}

Table 1 shows the cell viability determined by TBDE after $6 \mathrm{~h}$ of SM exposure, in the presence or absence of trolox or quercetin treatment. Cytotoxicity caused by SM was concentration-dependent and viability of the control cells was significantly lost at $80 \mathrm{mM}$ onwards. Almost 50\% cell death was caused by $80 \mathrm{mM}$ SM, whereas $100 \%$ cell death was observed at $640 \mathrm{mM}$. Pretreatment of trolox conferred significant protection at all the concentrations except 640 $\mathrm{mM}$. Also, simultaneous treatment and post-treatment of trolox protected the cells, but the effects were not statistically significant as compared with control. Treatment with quercetin offered only marginal protection. Further study was carried out with only $80 \mathrm{mM} \mathrm{SM}$, which was challenged by 
Table 1

Effect of various concentrations of sulfur mustard (SM) on the viability of human PBLs, in the presence or absence of various treatments of antidote, $10 \mathrm{mM}$ trolox or quercetin

\begin{tabular}{|c|c|c|c|c|}
\hline \multirow[t]{2}{*}{ Treatment } & \multirow[t]{2}{*}{ Concentration of $S M(\mu M)$} & \multicolumn{3}{|c|}{$\begin{array}{c}\text { Percent viability of cells by TBDE after } 6 \mathrm{~h} \text { of SM after treatment } \\
\text { Time of addition of antidotes }(h)\end{array}$} \\
\hline & & -0.5 & 0 & +0.5 \\
\hline Control & - & $93.8 \pm 6.6$ & $88.7 \pm 8.7$ & $95.6 \pm 5.8$ \\
\hline \multirow[t]{6}{*}{ SM } & 20 & $81.3 \pm 2.3$ & $82.3 \pm 6.2$ & $95.6 \pm 8.2$ \\
\hline & 40 & $78.6 \pm 7.3$ & $73.8 \pm 4.2$ & $78.9 \pm 8.6$ \\
\hline & 80 & $41.1 \pm 4.6^{a}$ & $55.9 \pm 4.5^{a}$ & $46.9 \pm 3.8^{a}$ \\
\hline & 160 & $35.4 \pm 1.1^{a}$ & $24.5 \pm 2.9^{a}$ & $32.6 \pm 4.3^{a}$ \\
\hline & 320 & $5.5 \pm 0.67^{a}$ & $11.2 \pm 1.8^{a}$ & $5.7 \pm 0.68^{a}$ \\
\hline & 640 & $0.0^{a}$ & $0.0^{a}$ & $0.0^{a}$ \\
\hline \multirow[t]{6}{*}{$\mathrm{SM}+$ trolox } & 20 & $88.9 \pm 8.9$ & $89.9 \pm 9.6$ & $92.3 \pm 9.7$ \\
\hline & 40 & $81.7 \pm 6.5$ & $83.5 \pm 8.6$ & $84.7 \pm 7.7$ \\
\hline & 80 & $79.0 \pm 5.7^{b}$ & $67.7 \pm 4.6$ & $50.7 \pm 3.3^{a}$ \\
\hline & 160 & $75.8 \pm 5.5^{b}$ & $59.5 \pm 3.9^{a, b}$ & $54.3 \pm 5.9^{a, b}$ \\
\hline & 320 & $75.5 \pm 6.5^{b}$ & $35.5 \pm 3.3^{a, b}$ & $35.7 \pm 6.9^{a, b}$ \\
\hline & 640 & $13.1 \pm 1.3^{a, b}$ & $5.6 \pm 1.8^{a, b}$ & $11.1 \pm 2.2^{a, b}$ \\
\hline \multirow[t]{6}{*}{$\mathrm{SM}+$ quercetin } & 20 & $89.9 \pm 6.9$ & $89.9 \pm 7.6$ & $78.3 \pm 8.9$ \\
\hline & 40 & $78.9 \pm 6.9$ & $76.6 \pm 7.7$ & $73.8 \pm 4.4$ \\
\hline & 80 & $59.3 \pm 5.9^{a}$ & $56.4 \pm 5.2^{a}$ & $59.7 \pm 6.2^{a}$ \\
\hline & 160 & $29.7 \pm 4.5^{a}$ & $50.2 \pm 3.5^{a, b}$ & $26.0 \pm 4.5^{a}$ \\
\hline & 320 & $25.8 \pm 3.8^{a, b}$ & $36.4 \pm 4.9^{a, b}$ & $19.3 \pm 1.7^{a, b}$ \\
\hline & 640 & $12.1 \pm 0.63^{a, b}$ & $1.9 \pm 0.0^{a, b}$ & $9.5 \pm 0.49^{a, b}$ \\
\hline \multirow[t]{3}{*}{ One-way ANOVA } & $\mathrm{F}$ & 38.7 & 33.6 & 32.8 \\
\hline & $\mathrm{df}$ & 75 & 75 & 75 \\
\hline & $\mathrm{P}$ & $<0.0001$ & $<0.0001$ & $<0.0001$ \\
\hline
\end{tabular}

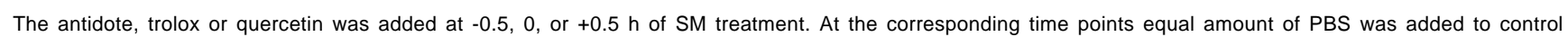
and SM treatment. Values are mean \pm SE $(n=4)$. ${ }^{a}$ Compared with control. ${ }^{b}$ Compared with SM treatment at P<0.05 (Student-Newman-Keuls test).

pretreatment with trolox or quercetin (Table 2). Significant reduction in cell viability accompanied by leakage of intracellular LDH and decrease in mitochondrial succinate dehydrogenase activity (MTT assay) were observed following treatment with $80 \mathrm{mM}$ SM. Both cell viability and LDH leakage was significantly prevented by pretreatment with trolox. Although MTT assay showed attenuation, the protection by trolox was not significant. Pretreatment of quercetin did not afford protection on any of the end points evaluated. The percent peroxide levels generated by SM, in the presence or absence of trolox or quercetin, was also quantified after 6-h exposure (data not presented). The peroxide level (percent of control) was significantly elevated to $198.6 \pm 12.9$ by $80 \mathrm{mM}$ by SM, which was reduced to $112.9 \pm 14.6$ and $156.9 \pm 16.9$ by pretreatment of trolox and quercetin, respectively. Although both the agents reduced the levels of peroxide, the effect of trolox was significant. Figure 1 shows the photomicrographs of lymphocytes treated with a cytotoxic concentration $(320 \mathrm{mM})$ of SM in the presence or absence of pretreatment with trolox or quercetin. Compared with the normal control cells [panel (A)], the SM-treated cells were

\section{Table 2}

Effect of $80 \mathrm{mM} \mathrm{SM}$ on the viability of human PBLs, in the presence or absence of pretreatment $(-0.5 \mathrm{~h})$ with $10 \mathrm{mM}$ trolox or quercetin

\begin{tabular}{|c|c|c|c|c|}
\hline \multicolumn{2}{|c|}{ Treatment } & $\begin{array}{c}\% \text { viability } \\
\text { by TBDE }\end{array}$ & $\begin{array}{l}\% \text { leakage } \\
\text { of } \mathrm{LDH}\end{array}$ & $\begin{array}{c}\text { MTT assay } \\
\left({ }_{\Delta} O D^{570}\right)\end{array}$ \\
\hline \multicolumn{2}{|l|}{ Control } & $90.5 \pm 0.91$ & $15.7 \pm 2.7$ & $0.441 \pm 0.038$ \\
\hline \multicolumn{2}{|l|}{ SM } & $56.7 \pm 9.9^{a}$ & $68.8 \pm 7.8^{a}$ & $0.194 \pm 0.062^{a}$ \\
\hline \multicolumn{2}{|c|}{$\mathrm{SM}+$ trolox } & $73.6 \pm 6.9$ & $23.3 \pm 2.7^{b}$ & $0.293 \pm 0.032^{a}$ \\
\hline \multicolumn{2}{|c|}{ SM + quercetin } & $48.5 \pm 6.3^{a}$ & $59.6 \pm 5.8^{a}$ & $0.190 \pm 0.014^{a}$ \\
\hline One-way & $\mathrm{F}$ & 7.50 & 25.4 & 8.45 \\
\hline \multirow[t]{2}{*}{ ANOVA } & df & 15 & 15 & 15 \\
\hline & $\mathrm{P}$ & $<0.0044$ & $<0.0001$ & $<0.0027$ \\
\hline
\end{tabular}

Viability of the cells was determined after 6-h exposure. In antidotetreated groups, trolox or quercetin was added at $-0.5 \mathrm{~h}$ of SM treatment. At the corresponding time point, equal amount of PBS was added to control and SM treatment. Values are mean \pm SEM $(n=4)$. ${ }^{a}$ Compared with control. ${ }^{b}$ Compared with SM treatment at $P<0.05$ by one-way ANOVA followed by Student-Newman-Keuls test. 
Figure 1. Photomicrograph of human PBLs cultured in 24-well plates and observed under light microscope. Cells were stained with Papanicolaous solution 3b. (A) Control cells showing normal morphology, round shape, and intact plasma membrane after $6 \mathrm{~h}$ of culture. (B) Cells exposed to $320 \mathrm{mM}$ SM for $6 \mathrm{~h}$, showing complete lysis and loss of cell viability. (C) Cells pretreated ( $-0.5 \mathrm{~h})$ with trolox (10 mM) and then exposed to $320 \mathrm{mM} \mathrm{SM}$ for $6 \mathrm{~h}$, showing significant cytoprotection. Restoration of cell morphology and viability are evident, but plasma membrane integrity of many cells is still compromised. (D) Cells pretreated $(-0.5 \mathrm{~h})$ with quercetin $(10 \mathrm{mM})$ and then exposed to $320 \mu \mathrm{M}$ SM, showing intact morphology, but TBDE revealed only $25-30 \%$ viability at this stage $(400 \mathrm{x})$.
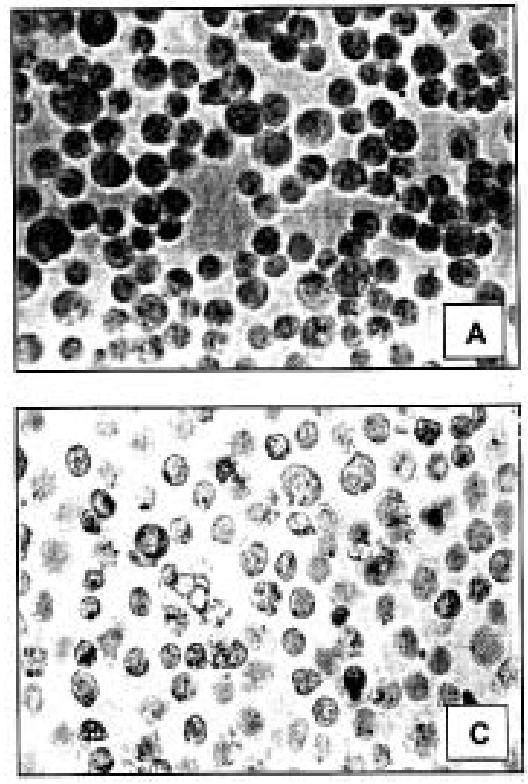

completely lysed without any intact morphology or plasma membrane integrity [panel (B)]. However, cells pretreated with trolox showed near-normal morphology of the cells with intact plasma membrane [panel (C)]. Although morphology of the cells protected with quercetin [panel (D)] was almost similar to those treated with trolox, the TBDE of the cells revealed only $25-30 \%$ cell viability.

\section{Discussion}

Various in vitro models have been used to delineate SM toxicity or its antagonism, but human lymphocyte culture is a model with many advantages. ${ }^{|23|}$ Previous study from this laboratory revealed that pretreatment of trolox, but not quercetin, was cytoprotective against cyanide poisoning in vitro. ${ }^{[19]}$ In view of the oxidative injury reported with SM toxicity, we evaluated the effects of pretreatment, simultaneous treatment, or post-treatment of trolox or quercetin against the same in human lymphocytes in vitro. SM causes cytotoxicity through lipid peroxidation, which is mediated by depletion of reduced glutathione (GSH). ${ }^{[3]}$ Flavonoids (gossypin and hydroxyethyl rutaside) and vitamin E have been shown to decrease SM-induced lipid peroxidation in mice, and this protection is attributed to their possible antioxidant and free-radical scavenging properties. ${ }^{[7]}$

In the present study, the dose-response of SM was similar to that observed previously in liver slice culture, but the severity of toxicity was more. ${ }^{[12]}$ Pretreatment with trolox generally protected against the cell membrane-damaging effects (TBDE, LDH release) of SM, but did not protect the mitochondrial activity, which is more sensitive to free radicals.
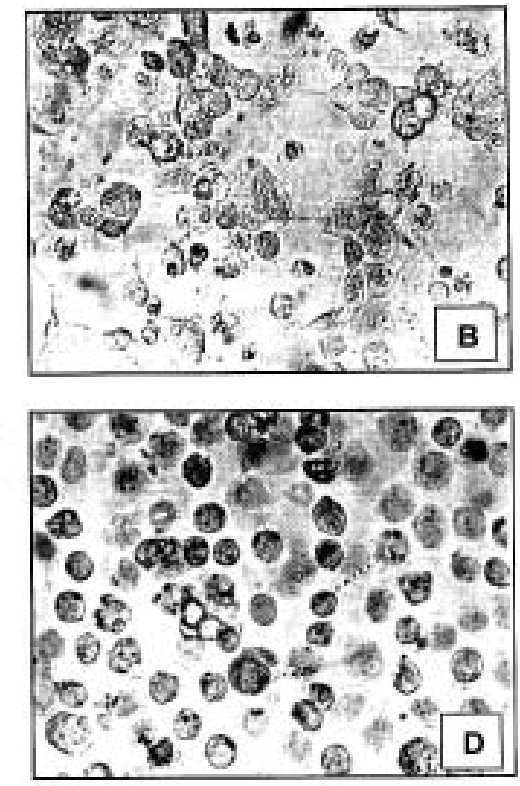

Perhaps, the diminished mitochondrial activity was sufficient to sustain the cell viability and would have restored to normalcy at a later stage. Trolox, however, protects cyanideinduced DNA fragmentation and mitochondrial and nuclear dysfunction by attenuating the peroxide levels in thymocytes in vitro. ${ }^{[19]}$ Reactive oxygen species mediated cytotoxicity and DNA damage is usually accompanied by depletion of intracellular GSH. ${ }^{[24]}$ Trolox is known to penetrate biomembranes and protect mammalian cells from oxidative damage and DNA fragmentation, and it is considered to be more potent than vitamin E. ${ }^{\mid 25]}$ Generation of free radicals is considered to be one of the earliest events preceding cell death. ${ }^{241}$ Because of this reason cells pretreated with the antioxidants could only show significant protection as compared with simultaneous or post-treatment. Lymphocytes are known to lack the ability to synthesize cysteine, a primary component for GSH, and its intracellular glutathione level depends largely on the extracellular cysteine. Therefore, GSH-mediated protection by trolox cannot be anticipated as observed in case of NAC, a precursor to glutathione. ${ }^{[26]}$ Antioxidant properties of quercetin is ascribed to its ability to interrupt membrane lipid peroxidation rather than scavenging the free radicals, which is excessively generated in SM toxicity. Perhaps for this reason we did not observe appreciable protection by quercetin. Also, in our previous study we did not observe notable protection by quercetin. ${ }^{[19]}$ The present study also indicates that trolox was better than quercetin in terms of reducing the levels of peroxide generated by SM. This also suggests strong antioxidant property of trolox, which has been widely 
recognized for many pathological conditions. ${ }^{[25]}$ In view of the present findings, prophylactic implications of trolox alone or with other agents cannot be overlooked against SM poisoning. Detailed animal studies would further validate its scope.

\section{Acknowledgment}

The authors thank Er. K. Sekhar, Director, DRDE, Gwalior, for providing keen support and encouragement in this work.

\section{References}

1. Krutzch W, Trapp RA. A commentary on the chemical weapons convention. London: Martinus Nijhoff Publishers; 1994.

2. Dacre JC, Goldman M. Toxicology and pharmacology of the chemical warfare agent sulfur mustard. Pharmacol Rev 1996;48:290-326.

3. Papirmeister B, Feister AJ, Robinson SI, Ford RD. Medical defense against mustard gas: toxic mechanisms and pharmacological implications. Boca Raton: CRC Press; 1991.

4. Wormser U. Toxicology of mustard gas. Trends Pharmacol Sci 1991;12:164-7.

5. Lakshmana Rao PV, Vijayaraghavan R, Bhaskar ASB. Sulfur mustardinduced DNA damage in mice after dermal and inhalation exposure. Toxicology 1999;139:39-51.

6. Somani SM, Babu SR. Toxicodynamics of sulfur mustard. Int J Clin Pharmacol Ther Toxicol 1989;27:419-35.

7. Vijayaraghavan R, Sugendran K, Pant SC, Husain K, Malhotra, RC. Dermal intoxication of mice wih bis (2-chloroethyl) sulfide and the protective effect of flavonoids. Toxicology 1991;69:35-42.

8. Gross CL, Innace JK, Hovatter RC, Meier HL, Smith WJ. Biochemical manipulation of intracellular glutathione levels influences cytotoxicity to isolated human lymphocytes by sulfur mustard. Cell Biol Toxicol 1993:9:259-68.

9. Lindsay $\mathrm{CD}$, Hambrook JL, Lailey AF. Monoisopropylglutathione ester protects A549 cells from cytotoxic effects of sulfur mustard. Hum Exp Toxicol 1997;16:636-44.

10. Meier HL, Johnson JB. The determination and prevention of cytotoxic effects induced in human lymphocytes by alkylating agent 2,2'-dichloroethyl sulfide (sulfur mustard, HD). Toxicol Appl Pharmacol 1992;113:234-9.

11. Vojvodic V, Milosavljevic Z, Boskovic B, Bojanic N. The protective effect of different drugs in rats poisoned by sulfur and nitrogen mustards. Fundam
Appl Toxicol 1985;5:S160-8.

12. Bhattacharya R, Lakshmana Rao PV, Pant SC, Kumar P, Tulsawani RK, Pathak $U$, et al. Protective effects of amifostine and its analogues on sulfur mustard toxicity in vitro and in vivo. Toxicol Appl Pharmacol 2001;176:2433.

13. Walker IG, Smith WJ. Protection of L-cells by thiols against the toxicity of sulfur mustard. Can J Physiol Pharmacol 1969;47:143-51.

14. Das SK, Mukherjee S, Smith MG, Chatterjee D. Prophylactic protection by $\mathrm{N}$-acetylcesteine against the pulmonary injury induced by 2-chloroethyl sulfide, a mustard analogue. J Biochem Mol Toxicol 2003;17:177-84.

15. Shih MN, Korte WD, Smith JR, Szafraniec LL. Reactions of sulfides with S330 , a potential decontaminant of sulfur mustard in formulations. J Appl Toxicol 1999;19:83-8.

16. Vijayaraghavan R, Kumar P, Dubey DK, Singh R. Evaluation of CC2 as a decontaminant in various hydrophilic and lipophilic formulations against sulfur mustard. Biomed Environ Sci 2002;15:25-35

17. Tabatabaei AR, Thies RL, Farrell K, Abbott FS. A rapid in vitro assay for evaluation of metabolism-dependent cytotoxicity of antiepileptic drugs on isolated human lymphocytes. Fundam Appl Toxicol 1997;37:181-9.

18. Gad SC. In Vitro toxicology. $2^{\text {nd }}$ ed. New York: Academic Press; 2000.

19. Bhattacharya R, Lakshmana Rao PV. Pharmacological interventions of cyanide-induced cytotoxicity and DNA damage in isolated rat thymocytes and their protective efficacy in vivo. Toxicol Lett 2001;119:59-70.

20. Mitchell DB, Santone KS, Acosta D. Evaluation of cytotoxicity in cultured cells by enzyme leakage. J Tissue Culture Methods 1980;6:113-6.

21. Mosman T. Rapid colorimetric assay for cellular growth and survival: application to proliferation and cytotoxicity assays. J Immunol Methods 1983;65:55-63.

22. Koizumi T, Shirakura $H$, Kumagai $H$, Tatsumoto $H$, Suzuki KT. Mechanism of cadmium-induced cytotoxicity in rat hepatocytes: cadmium-induced active oxygen-related permeability changes of plasma membrane. Toxicology 1996;114:125-34.

23. Meir HL, Johnson JB. The determination and prevention of cytotoxic effects induced in human lymphocytes by the alkylating agent 2,2'-dichlorodiethyl sulfide (sulfur mustard, HD). Toxicol Appl Pharmacol 1992;113:234-9.

24. Nicotera P, Ankarcrona M, Bonfoco E, Orrenius S, Lipton SA. Neuronal necrosis and apoptosis: two distinct events induced by exposure to glutamate or oxidative stress. Adv Neurol 1997;72:95-101.

25. McClain DE, Kalinich JF, Ramakrishnan N. Trolox inhibits apoptosis in irradiated MOLT-4 lymphocytes. FASEB J 1995;9:1345-54.

26. Weltin D, Aupeix K, Iltis C, Cuillerot JM, Dufour P, Marchal J, Bischoff P. Nacetylcysteine protects lymphocytes from nitrogen mustard-induced apoptosis. Biochem Pharmacol 1996;51:1123-9.

\section{THIRD WORKSHOP ON DRUG DISCOVERY \& DEVELOPMENT IN NEW MILLENNIUM}

Date : February 21-24, 2005

Contact Person:

Dr. Shyam S. Sharma

D3NM Workshop Convener

Department of Pharmacology and Toxicology

National Institute of Pharmaceutical Education and Research

Sector 67, S.A.S. Nagar (Mohali) 160062, Punjab, INDIA

E-mail:sssharma@niper.ac.in 